University of Rhode Island

DigitalCommons@URI

Open Access Master's Theses

1968

\title{
Effects of Colloidal Silica on the Apparent Viscosity of White Petrolatum
}

Louis Gedeon Roy

University of Rhode Island

Follow this and additional works at: https://digitalcommons.uri.edu/theses

\section{Recommended Citation}

Roy, Louis Gedeon, "Effects of Colloidal Silica on the Apparent Viscosity of White Petrolatum" (1968). Open Access Master's Theses. Paper 222.

https://digitalcommons.uri.edu/theses/222

This Thesis is brought to you for free and open access by DigitalCommons@URI. It has been accepted for inclusion in Open Access Master's Theses by an authorized administrator of DigitalCommons@URI. For more information, please contact digitalcommons-group@uri.edu. 
EFFECTS OF COLLOIDAL SILICA

ㅇN

THE APPARENT VISCOSITY OF WHITE PETROLATUM

BY

LOUIS GEDEON ROY

A THESIS SUBMITTED IN PARTIAL FULFILLMENT OF THE REQUIREMENTS FOR THE DEGREE OF MASTER OF SCIENCE

IN

PHARMACEUTICAL SCIENCES

UNIVERSITY OF RHODE ISLAND

1968 
TITLE ABSTRACT

\author{
VISCOSITY \\ $\mathrm{OF}$ \\ SEMISOLID SYSTEMS
}




\section{ABSTRACT}

Three grades of colloidal silica (Cab-O-Sil CDL-5, M-5, and EH-5) of different particle size and specific surface were added to white petrolatum in concentrations of $0.25 \%, 0.5 \%, 1.0 \%$, and $2.0 \%$ by weight in an attempt to determine the effect of particle size and concentration of the silica on the rheological properties of the petrolatum. Rheological properties were determined with a modified Stormer viscosimeter. Increasing concentrations of silica within a particle size grade caused an increase of apparent viscosity of the petrolatum at almost all rates of shear. The effect of particle diameter on apparent viscosity was found not to be strictly in order of decreasing particle size, as was expected, although the largest particle size grade (CDL -5$)$ was the least effective of the three grades used. A possible explanation for the anomalous results would be either that the initial dispersion of the Cab-O-Sil in white petrolatum was not complete due to the limitations of the ointment mill used, or that subsequent particle agglomeration took place. In general, the apparent viscosity at all shear rates increased with aging of the samples, an effect that probably indicates structural reformation of white petrolatum with time: 


\section{MASTER OF SCIENCE THESIS}

\section{OF}

LOUIS GEDEON ROY

\section{Approved:}

\section{Thesis Committee:}

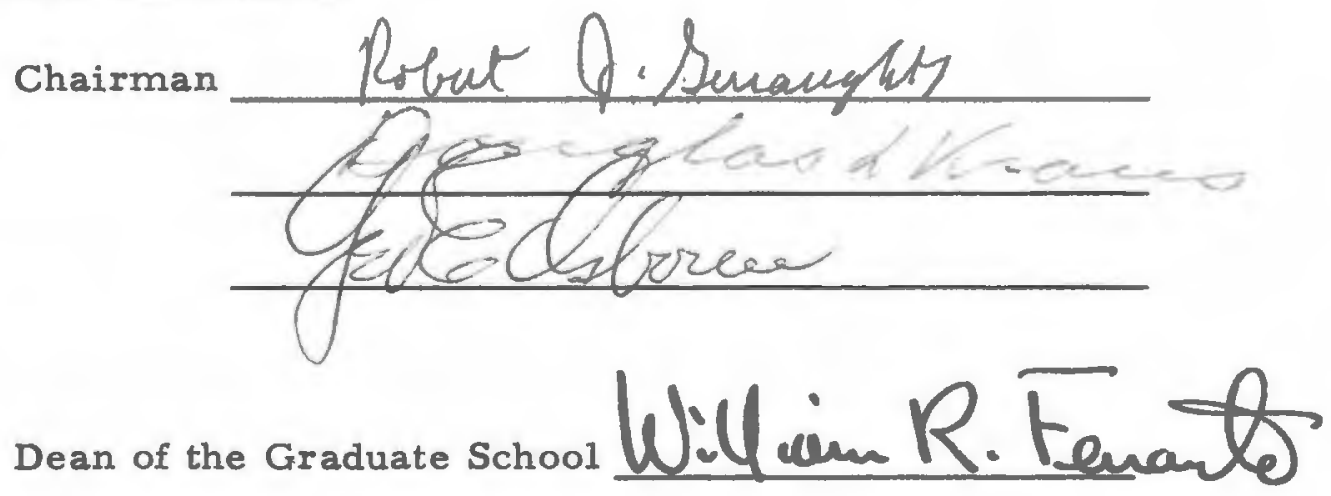

UNIVERSITY OF RHODE ISLAND 
TABLE OF CONTENTS

PAGE

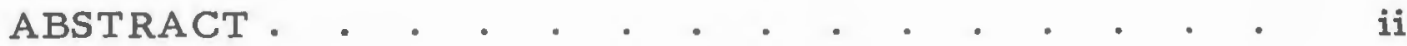

TABLE OF CONTENTS • . . . . . . . . . . . . iii

LIST OF TABLES • • • • • • • • • • • • • iv

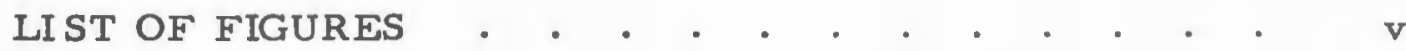

I. INTRODUCTION •

II. EXPERIMENTAL $\cdot$ •

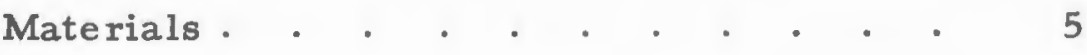

Instrumentation . . . . . . . . . 6

Calibration of Instrument . . . . . . 9

Sample Preparation . . . . . . . . 11

Rheological Evaluation • . . . . . . 12

III. RESULTS AND DISCUSSION $\quad \cdot \quad \cdot \quad \cdot \quad \cdot \quad \cdot 13$

Effect of Solid Addition . . . . . . . 13

Effect of Particle Diameter and

Specific Surface. . . . . . . . . 13

Effect of Aging . . . . . . . . . . 25

IV. CONCLUSIONS • • • . • • • • • • 30

V. REFERENCES • • • • • • • • • • • 31 


\section{LIST OF TABLES}

TABLE

PAGE

I. The Effect of Colloidal Silica (Cab-O-Sil Grade CDL-5) on the Apparent Viscosity of White Petrolatum . . . . . . . . .

II. The Effect of Colloidal Silica (Cab-O-Sil Grade $M-5$ ) on the Apparent Viscosity of White Petrolatum . . . . . . . . .

III. The Effect of Colloidal Silica (Cab-O-Sil Grade $\mathrm{EH}-5$ ) on the Apparent Viscosity of White Petrolatum . . . . . . . . .

IV. The Effect of Particle Size or Specific Surface of Colloidal Silica on the Apparent Viscosity of White Petrolatum . . . . .

V. The Effect of Particle Size or Specific Surface of Colloidal Silica on the Apparent Viscosity of White Petrolatum . . . . .

VI. The Effect of Sample Aging on the Apparent Viscosity of White Petrolatum

VII. The Effect of Sample Aging on the Apparent Viscosity of a Mixture of Colloidal Silica (Cab-O-Sil Grade EH-5) and White Petrolatum 


\section{LIST OF FIGURES}

FIGURE

PAGE

1. Photograph of Modified Rheometer and its Components . . . . . . . . . . .

2. Schematic Diagram of Electronic Tachometer . . . . . . . . . . . . .

3. Apparent Viscosity vs. Elapsed Shearing Time for the Various Concentrations of Cab-O-Sil Grade CDL-5 . . . . . .

4. Apparent Viscosity vs. Elapsed Shea ring Time for the Various Concentrations of Cab-O-Sil Grade M-5 . . . . . . .

5. Apparent Viscosity vs. Elapsed Shearing Time for the Various Concentrations of Cab-O-Sil Grade EH-5 . . . . . . . .

6. Apparent Viscosity vs. Elapsed Shearing Time for the Various Grades of Cab-O-Sil at a Concentration of $0.5 \%$. . . . .

7. Apparent Viscosity vs. Elapsed Shearing Time for the Various Grades of Cab-O-Sil at a Concentration of $0.25 \%$. . . . .

8. Apparent Viscosity vs. Elapsed Shearing Time for Three Sample Ages of White Petrolatum . . . . . . . . .

9. Apparent Viscosity vs. Elapsed Shearing Time for Three Sample Ages of Cab-O-Sil Grade EH-5, at a Concentration of $1.0 \%$. . 


\section{INTRODUCTION}

The science that deals with the flow of liquids and the deformation of solids is known as rheology. Studies concerned with the utilization of the principles of this science are generally divided into two classes: those which are concerned with homogeneous systems and those which are concerned with heterogeneous, dispersed systems. Flow characteristics are usually described graphically in terms of rate of shear vs. shearing stress; and substances for which a straight-line relationship can be established are referred to as being Newtonian in character. Substances for which such a relationship cannot be established are referred to as being non-Newtonian; and because of their greater physical complexity, they demonstrate unique characteristics of flow when they are subjected to an applied force.

Problems confronting the pharmaceutical industry in the manufacture of such pharmaceutical dosage forms as suspensions, emulsions, creams, and ointments become very complex, because these classes of dose forms are not only heterogeneous, dispersed systems, but they also exhibit non-Newtonian flow characteristics. The complexity of quantifying the flow characteristics of these multi-component systems, with the aim of product duplication in the industrial setting, provides the impetus for research in this area. However, the paucity of 
literature in the field is indicative of the difficulty of the problem.

The earliest reported work in the area was carried out in an attempt to define the rheological parameters of ointments and ointment bases. Kostenbauder and Martin (1) found that the quantitative determination of the rheological properties of pharmaceutical semisolids could best be accomplished by measurement of the three rheological parameters: (1) viscosity, (2) yield value, (3) thixotropy.

Boylan (2), in a study of the effect of temperature on thirteen pharmaceutical semisolids, showed that increases in temperature produced decreases in all three of these parameters.

Schulte and Kassem (3) found that petrolatum consisted of three paraffinic fractions ( $n$, iso, and cyclic). They attributed the rheological behavior of this semisolid to the ratio of the forms present. They further stated that when subjected to stress, structural collapse of the n-paraffins was greater than the iso-paraffins. Also, they noted that the n-paraffinic form possessed the largest crystallite structure.

Boylan (4) also conducted a study in an attempt to rheologically evaluate the spreading characteristics of ointment bases. His results showed that in the case of white petrolatum at shear rates of $120 \mathrm{sec}^{-1}$, greatest resistance to flow occurred. He postulated that, at rest, petrolatum has a three dimensional gel structure which consists of random entanglement and chemical bonding of its three paraffinic fractions. As shear rate is increased, alignment of the 
$\mathrm{n}$-parafinnic form in the direction of shear occurs while the iso and cyclic paraffins do not readily align.

Included in the Kostenbauder and Martin study (5) was a series of experiments designed to show the effect of the incorporation of certain solids into ointment bases. White wax and zinc oxide powder were added both to white petrolatum and to a mixture of white petrolatum and mineral oil. From their results, they concluded that, as the percent concentration of either white wax or of zinc oxide was increased, all three rheological parameters, viscosity, yield value, and thixotropy, increased. While the Kostenbauder and Martin work employed additives of two distinctly different characters, both substances are recognized in the official compendia; however, the official specifications provide nothing more than quality control of the items listed.

It was therefore considered that additives of controlled particle size, and hence specific surface, might be used to make a more quantitative evaluation of the effects of incorporating a solid material into an ointment base. Colloidal silica is commercially available as Cab-O-Sil; it is guaranteed by the manufacturer to consist of spherical particles of a given particle size and specific surface, and is graded according to particle size. Paralleling past studies by using white petrolatum as the external phase in the model system, but incorporating into it various grades of colloidal silica of controlled particle size, this investigator proposed to conduct a rheological study of the relationship between 
particle size and specific surface of added solid material and the apparent viscosity of the semisolid base. Simultaneously, the effect of concentration of additive in the system was observed. Also, the effect of sample aging on apparent viscosity was studied. 


\section{EXPERIMENTAL}

Materials - The solid material selected was Cab-O-Sil because of its large specific surface, uniform particle size, and uniform spherical shape. In order to provide a sufficient difference in particle size, the CDL-5, M-5 and EH-5 grades were used. The CDL-5 grade has an average particle diameter of $0.05 \mu$, is spherical in shape, and has a specific surface of $50 \mathrm{~m}^{2} / \mathrm{gm}$. The $\mathrm{M}-5$ grade has an average particle diameter of $0.012 \mu$, is spherical in shape, and has a specific surface of $200 \mathrm{~m}^{2} / \mathrm{gm}$. The third grade $\mathrm{EH}-5$ has an average particle diameter of $0.007 \mu$, is also spherical in shape, and has a specific surface of $390 \mathrm{~m}^{2} / \mathrm{gm}$. Three concentrations of each grade were prepared to obtain a comparison within each of the three grades, and to develop the relationship between concentration, specific surface, and apparent viscosity. Rheograms of each sample were obtained at three different ages to illustrate the extent of thixotropic recovery.

White Petrolatum U.S. P. ${ }^{2}$ was selected as the ointment base because of its widespread use in dermatological products. In addition, it was used in a similar study by Kostenbauder and Martin (6). All

\footnotetext{
${ }^{1}$ Cabot Corporation, Oxides Division, 125 High Street, Boston, Massachusetts.

${ }^{2}$ Amend Drug \& Chemical Co., 117-119 East 24th Street, New York, New York.
} 
samples of white petrolatum were obtained from the same $50 \mathrm{lb}$. container which was stored at room temperature.

Instrumentation - The Stormer viscosimeter, as originally designed, cannot be used to obtain meaningful results in rheological problems dealing with semisolid systems. Consequently, it was necessary to make certain modifications. The modifications were: replacing the conventional cup and bob with a cone and plate; and the use of a recording tachometer to directly obtain rates of shear during the shearing process. Figure 1 shows a photograph of the modified rheometer and its components.

The cone was made from aluminum; it had a radius of $0.820 \mathrm{~cm}$., and a cone angle constant of $0.7429^{\circ}$. The plate was of the liquid circulating type, was approximately $5 \mathrm{~cm}$. long on each side, and was nickel plated. The circulating stage was connected to a constant temperature water bath ${ }^{1}$ to maintain sample temperature at $25^{\circ} \mathrm{C}$. $\pm 0.5^{\circ} \mathrm{C}$.

The electronic tachometer circuit is shown in Figure 2. Light from the number forty-seven lamp is interrupted by a Ronchi ruling on film (40 lines/inch) driven by the viscosimeter spindle. Interruption of the light beam causes the photocell to generate an electrical signal with a frequency proportional to the rate of rotation of the spindle. This signal, amplified by the transistors $Q_{1}$ and $Q_{2}$, is fed through a

\footnotetext{
${ }^{1}$ Mode1 3052, Labline Instruments Inc., Chicago, Illinois
} 


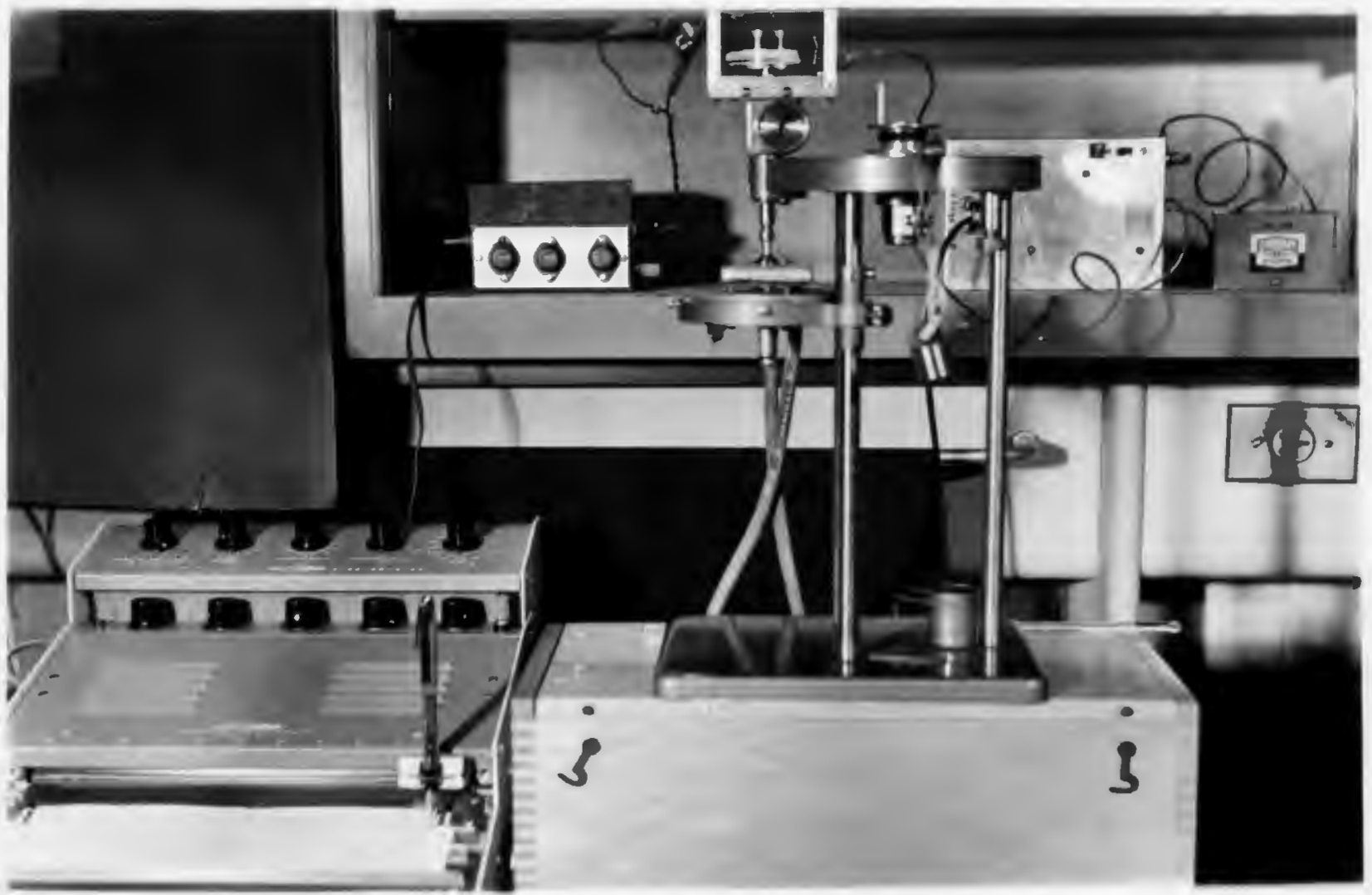

Figure 1. Photograph of Modified Rheometer and its Components. 


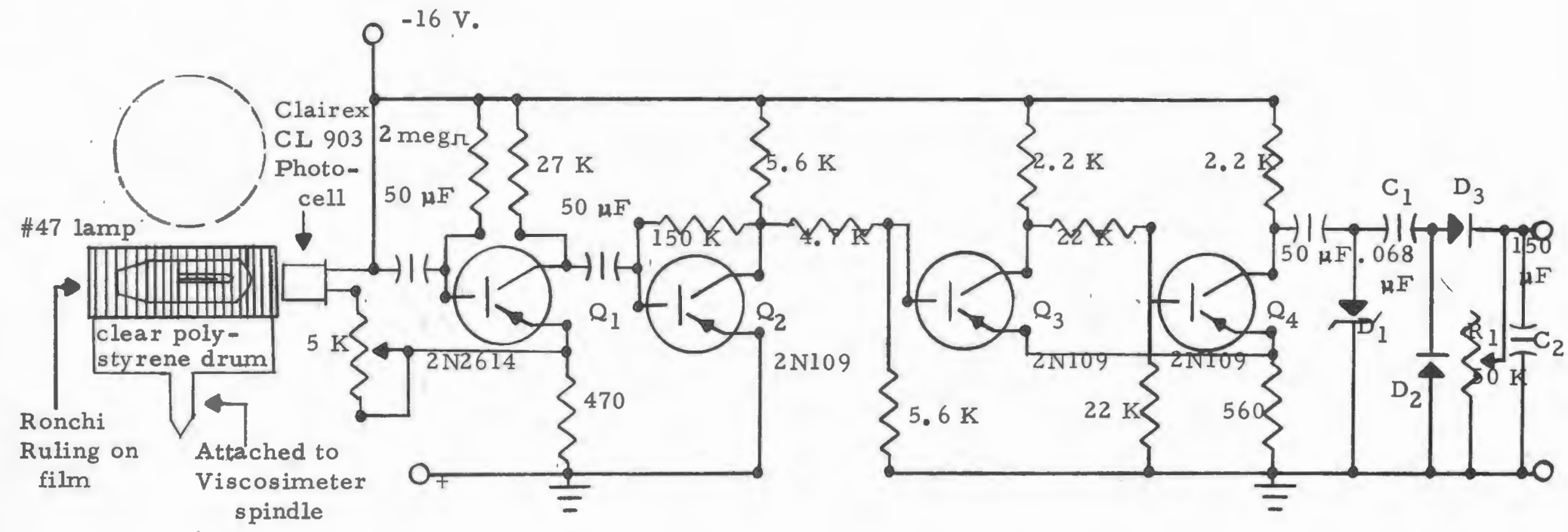

Figure 2. Schematic Diagram of Electronic Tachometer. 
Schmidt trigger and Zenner diode $\left(Q_{3}, Q_{4}, D_{1}\right)$ to give a square wave signal of uniform amplitude. The square wave signal then goes through a diode pump $\left(C_{1}, D_{2}, D_{3}\right)$ and an averaging capacitor $\left(C_{2}\right)$ to yield a direct current output signal with an amplitude proportional to the rate of rotation of the viscosimeter spindle. Variable resistor, $R_{1}$, permits adjustment of the output signal to a convenient level for recording and calibration. This tachometer circuit was electrically connected to a recording $\mathrm{pH}$ meter ${ }^{1}$.

Calibration of Instrument - This procedure was divided into two different operations: the determination of the viscosimeter cone angle and the calibration of the recording tachometer.

(1) Determination of viscosimeter cone angle

The mathematical determination of the cone angle required the use of a modified form of the following equation (7):

$$
\eta=\frac{3 G \psi}{2 \pi R^{3} \Omega}
$$

where:

$$
\begin{aligned}
& G=\text { torque (dynes/cm.) } \\
& R=\text { radius of cone }(\mathrm{cm} .) \\
& \Omega=\text { rotational velocity (radians/sec) } \\
& \eta=\text { viscosity (poises) } \\
& \psi=\text { cone angle (radians) }
\end{aligned}
$$

The rotational velocity value was obtained using Medical Fluid $360^{2}$.

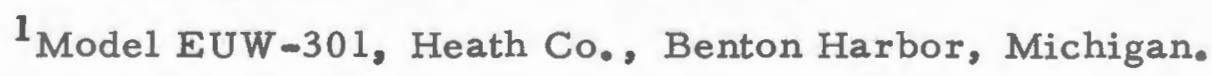

2 Dow Corning Corporation, Midland, Michigan. 
A Brookfield viscometer ${ }^{1}$ was used to determine the viscosity of this fluid. The experimental value obtained for the viscosity of the fluid agreed with that cited by the manufacturer. The torque transmitted to the rotating cone was obtained from the following equation (8):

$$
M=\frac{R \times g \times W}{11.0}
$$

where:

$$
\begin{aligned}
\mathbf{R} & =\text { radius of winding drum }(\mathrm{cm}) \\
\mathbf{M} & =\text { torque transmitted to rotor }(\text { dynes }-\mathrm{cm}) \\
\mathrm{g} & =\text { gravitational force }\left(\mathrm{cm} / \mathrm{sec}^{2}\right) \\
\mathrm{W} & =\text { weight on string }(\text { grams }) \\
11.0 & =\text { gear ratio }
\end{aligned}
$$

The cone angle was calculated and found to be 0.7429 degrees or 0.01296 radians.

(2) Calibration of the recording tachometer

This procedure was carried out using Castor Oil U. S. P.

A sample of the oil was placed within the shearing space and allowed to equilibrate to a constant temperature of $25^{\circ} \mathrm{C}$. ; the cone was allowed to complete fifteen revolutions; and then timing was begun. All timing was carried out using a GraLab Microtimer ${ }^{2}$. The time required to complete a given number of revolutions was noted. This process was repeated three times and an average value taken. In most instances, time variation was of the order of $\pm 0.3 \mathrm{sec}$. A value for

\footnotetext{
${ }^{1}$ Model RVF, Brookfield Engineering Laboratory, Stoughton, Massachusetts.

${ }^{2}$ Dimco-Gray Company, Dayton, Ohio.
} 
r.p.m. was calculated from these observed data. Simultaneously, the recorder was charting the number of $r \cdot p_{0} m$. A correction was determined by taking the difference between the calculated value and the chart value.

The rotational velocity is directly proportional to rate of shear on the Stormer viscosimeter. Consequently, because of this existing straight-line relationship, conversion from r.p.m. to rate of shear became a simple process of interpolation.

Sample Preparation - All samples to be evaluated were prepared by a similar procedure. Ingredients were weighed on a torsion balance ${ }^{1}$. A sufficient amount of each ingredient was weighed to make 60 grams of the $0.25 \% \mathrm{Cab}-\mathrm{O}-\mathrm{Sil}$, grades $\mathrm{E} \Psi-5$ and $\mathrm{M}-5$ in white petrolatum. All other samples to be evaluated had a total weight of 30 grams. After weighing the ingredients, the powder for each sample was incorporated by hand on an ointment slab with a spatula into the smallest practicable amount of ointment base. The remainder of the ointment base, together with the mixture of ointment base and powder, were then passed through an Erweka Ointment $\mathrm{Mill}^{2}$ six times. By means of an applicator stick, a portion of the milled sample was placed on the viscosimeter liquid circulating plate and allowed to equilibrate to a constant

${ }^{1}$ Class A, The Torsion Balance Co., Clifton, New Jersey. ${ }^{2}$ Type SM, Distributor, Chemical and Pharmaceutical Industry Co., Inc., 90 West Broadway, New York 7, New York. 
temperature of $25^{\circ} \mathrm{C}$. All rheograms were obtained at this temperature. Rheograms were obtained for each sample within two hours of sample preparation and this determination time is designated as zero sample age in the data. Rheograms were also obtained after two days and after sixteen days from the day of preparation. In all instances, a fresh portion of the ointment was used to obtain each rheogram.

Rheological Evaluation - Rheograms of the systems under study were graphically recorded during the shearing process. In order to obtain meaningful results, it was necessary to calibrate the recorder paper before graphing the systems. The number of ruled lines on the recorder paper that passed a given point in a unit amount of time was noted. Therefore, it was possible to determine the amount of elapsed shearing time which each ruled line represented. Consequently, rates of shear could be determined at any given elapsed time during the shearing process. Apparent viscosities could be calculated at a specific elapsed time by dividing the rate of shear for a system at that given elapsed time into the shearing stress value. The shearing stress value was directly calculated from the force that was applied. 


\section{RESULTS AND DISCUSSION}

Effect of Solid Addition - The data presented in Tables I, II, and III and in Figures 3, 4, and 5 illustrate the effect of incorporation of various grades of Cab-O-Sil, at three different concentrations, on the apparent viscosity of white petrolatum. The tabulated data show that as concentration of solid material within a given grade is increased, the a pparent viscosity increases. Also, the figures show that a decrease of apparent viscosity is obtained with elapsed shearing time. These results are in agreement with those obtained by Kostenbauder and Martin (9) in a similar study. As is illustrated in Figure 4, the behavior of the $1 \%$ M-5 grade sample was anomalous in the region of 40 to 74 poises ( 190 to $100 \mathrm{sec}^{-1}$ ), with the most pronounced abnormality occurring at approximately 60 poises $\left(125 \mathrm{sec}^{-1}\right)$; the region referred to by Boylan (10) as possessing the greatest resistance to flow.

Effect of Particle Diameter and Specific Surface - Figure 6 indicates the possibility that a relationship exists between average particle diameter or specific surface of $\mathrm{Cab}-\mathrm{O}-\mathrm{Sil}$, and the apparent viscosity. A comparison of the apparent viscosities for three different grades of Cab-O-Sil at the same concentration is shown in Table IV. It is ex- 
TABLE I

THE EFFECT OF COLLOIDAL SILICA

(CAB-O-SIL GRADE CDL-5)

ON THE APPARENT VISCOSITY(a)

OF WHITE PETROLATUM

\begin{tabular}{|c|c|c|c|c|}
\hline \multirow{2}{*}{$\begin{array}{l}\text { Elapsed } \\
\text { Shearing } \\
\text { Time } \\
\text { (sec.) }\end{array}$} & \multirow[b]{2}{*}{0} & \multicolumn{3}{|c|}{ Percent Concentration Cab-O-Sil (b) } \\
\hline & & 0.50 & 1.0 & 2.0 \\
\hline 6 & 68.80 & 84.10 & 84.10 & 135. \\
\hline 30 & 19.70 & 16.58 & 32.90 & 59.20 \\
\hline 60 & 13.45 & 12.74 & 22.80 & 47.30 \\
\hline 90 & 10.81 & 12.46 & 21.80 & 41.40 \\
\hline 120 & 9.91 & 12.11 & 21.20 & 35.20 \\
\hline 180 & 8.50 & 11.52 & 18.45 & 25.50 \\
\hline 240 & - & 10.55 & 15.76 & 19.70 \\
\hline 300 & - & - & 14.11 & 17.50 \\
\hline 360 & - & - & 13.05 & 16.10 \\
\hline 420 & - & - & - & 14.95 \\
\hline
\end{tabular}

(a) Apparent viscosities in poises. Values shown represent average of at least two runs.

(b) Age of all samples -0- day. 


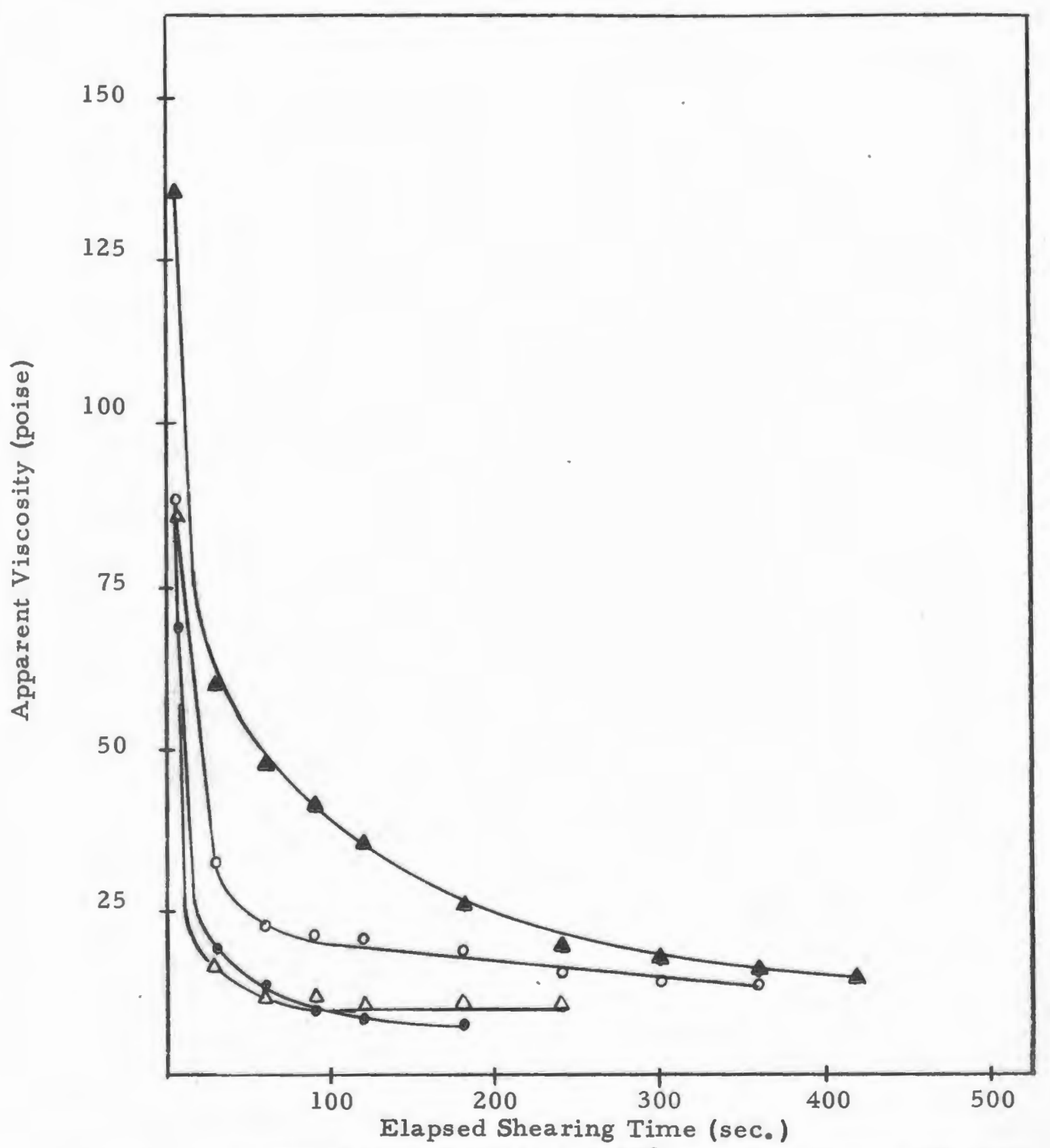

Figure 3. Apparent Viscosity (poise) at $25^{\circ} \mathrm{C}$. versus Elapsed Shearing Time (sec.) for the various concentrations of Cab-O-Sil, Grade CDL-5. All runs made at a shearing stress of 7570 dynes $/ \mathrm{cm}$. with sample age -0- day. $(\bullet=0 \% ; \Delta=0.5 \% ; 0=1.0 \% ; \Delta=2.0 \%)$ 
TABLE II

THE EFFECT OF COLLOIDAL SILICA

(CAB-O-SIL GRADE M-5)

ON THE APPARENT VISCOSITY(a)

OF WHITE PETROLATUM

\begin{tabular}{|c|c|c|c|c|}
\hline $\begin{array}{c}\text { Elapsed } \\
\text { Shearing } \\
\text { Time } \\
(\text { sec.) }\end{array}$ & 0 & \multicolumn{3}{|c|}{ Concentration $\mathrm{Cab}-\mathrm{O}-\mathrm{Sil}(\mathrm{b})$} \\
\hline 6 & 68.80 & 116.50 & 103.85 & 252.10 \\
\hline 30 & 19.70 & 37.80 & 45.00 & 116.50 \\
\hline 60 & 13.45 & 24.58 & 33.90 & 92.40 \\
\hline 90 & 10.81 & 19.70 & 25.50 & 78.20 \\
\hline 120 & 9.91 & 17.50 & 20.42 & 72.80 \\
\hline 180 & 8.50 & 13.75 & 15.76 & 68.80 \\
\hline 240 & - & 12.11 & 12.74 & 59.20 \\
\hline 300 & - & 11.10 & 11.52 & 42.80 \\
\hline 360 & - & - & - & 32.90 \\
\hline 420 & - & - & - & 24.58 \\
\hline 480 & - & - & - & 20.42 \\
\hline 540 & - & - & - & - \\
\hline
\end{tabular}

(a) Apparent viscosities in poises. Values shown represent average at least two runs.

(b) Age of all samples -0- day. 


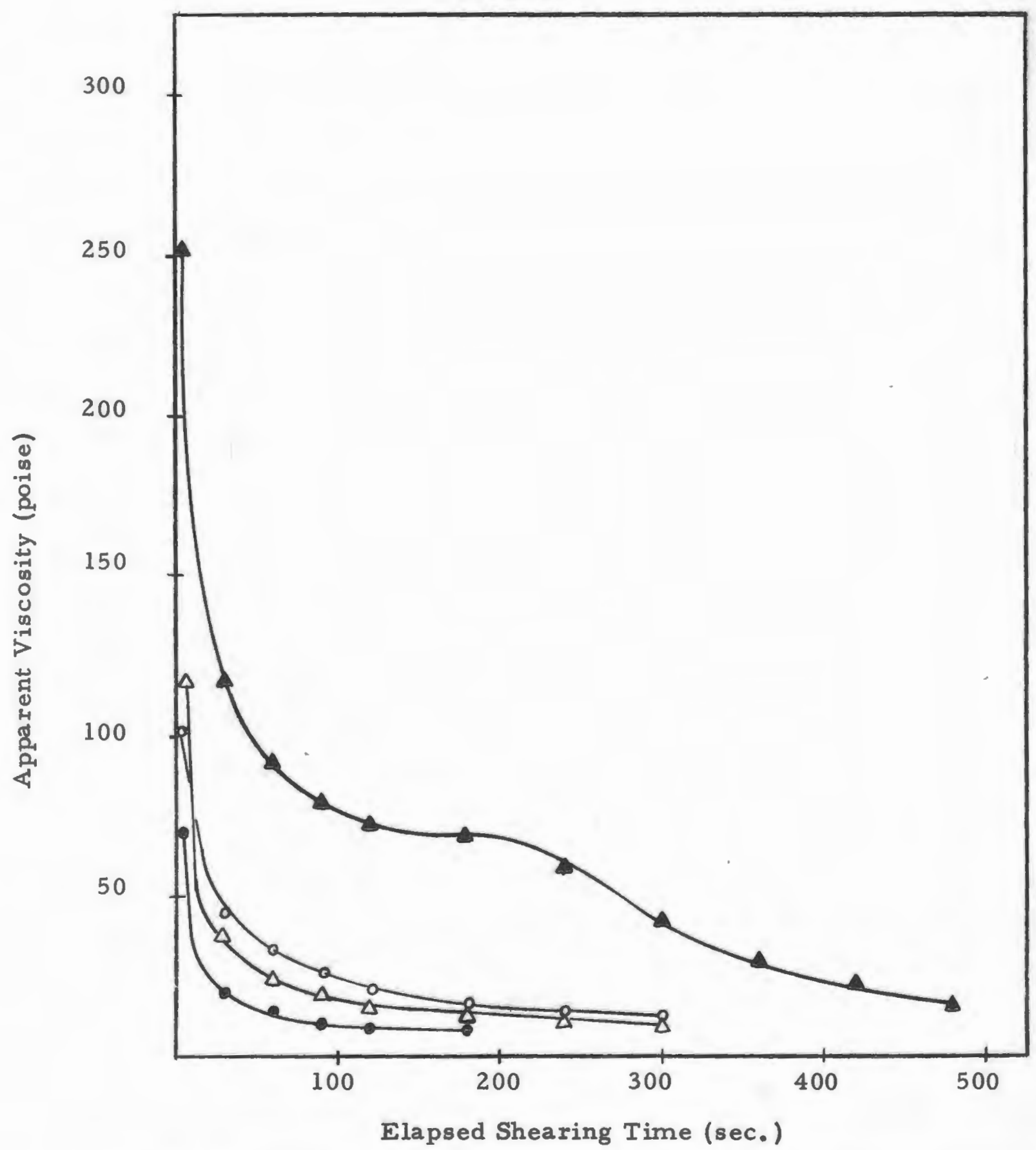

Figure 4. Apparent Viscosity (poise) at $25^{\circ} \mathrm{C}$. versus Elapsed Shearing Time (sec.) for the various concentrations of Cab-O-Sil, Grade M-5. All runs made at a shearing stress of 7570 dynes $/ \mathrm{cm}^{2}$ with sample age -0- day. $(\bullet=0 \% ; \Delta=0.25 \% ; 0=0.5 \% ; \Delta=1.0 \%)$ 
TABLE III

THE EFFECT OF COLLOIDAL SILICA

(CAB-O-SIL GRADE EH-5)

ON THE APPARENT VISCOSITY(a)

OF WHITE PETROLATUM

\begin{tabular}{|c|c|c|c|c|}
\hline \multirow{2}{*}{$\begin{array}{l}\text { Elapsed } \\
\text { Shearing } \\
\text { Time } \\
\text { (sec.) }\end{array}$} & \multicolumn{4}{|c|}{ Percent Concentration $\mathrm{Cab}-\mathrm{O}-\mathrm{Sil}^{(\mathrm{b})}$} \\
\hline & 0 & 0.25 & 0.50 & 1.0 \\
\hline 6 & 68.80 & 68.80 & 103.80 & 222.60 \\
\hline 30 & 19.70 & 20.42 & 39.60 & 78.10 \\
\hline 60 & 13.45 & 15.40 & 22.80 & 63.60 \\
\hline 90 & 10.81 & 13.75 & 18.90 & 54.50 \\
\hline 120 & 9.91 & 12.74 & 16.88 & 47.30 \\
\hline 180 & 8.50 & 11.52 & 14.95 & 33.90 \\
\hline 240 & - & 10.80 & 13.75 & 22.80 \\
\hline 300 & - & - & 12.74 & 17.50 \\
\hline 360 & - & - & - & 15.40 \\
\hline 420 & - & - & - & 14.12 \\
\hline
\end{tabular}

(a) Apparent viscosities in poises. Values shown represent average of at least two runs.

(b) Age of all samples -0- day. 


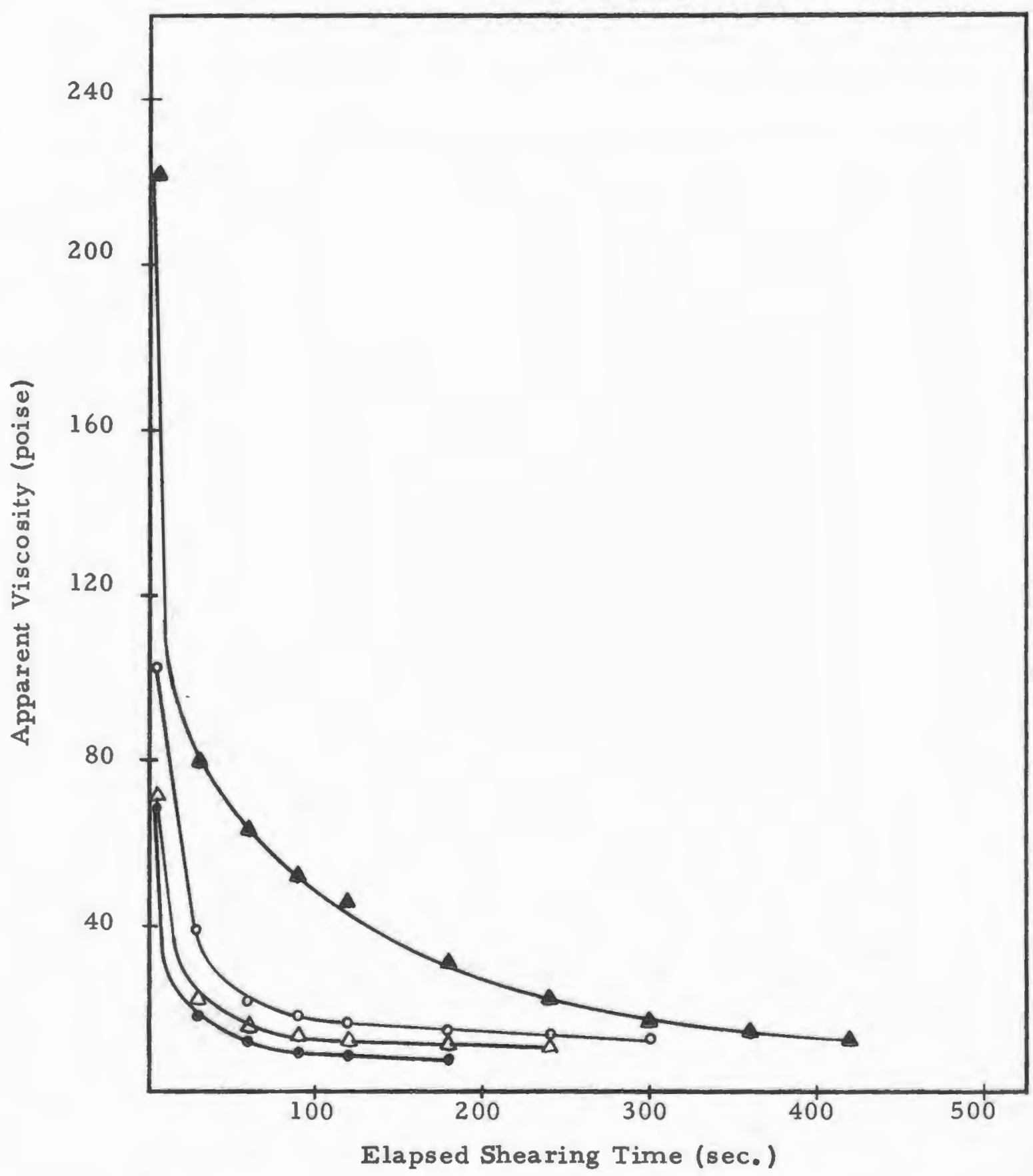

Figure 5. Apparent Viscosity (poise) at $25^{\circ} \mathrm{C}$. versus Elapsed Shearing Time (sec.) for the various concentrations of Cab-O-Sil, Grade EH-5. All runs made at a shearing stress of 7570 dynes $/ \mathrm{cm}, 2$ with sample age -0 - day. $(\bullet=0 \% ; \Delta=0.25 \% ; 0=0.5 \% ; \Delta=1.0 \%)$ 


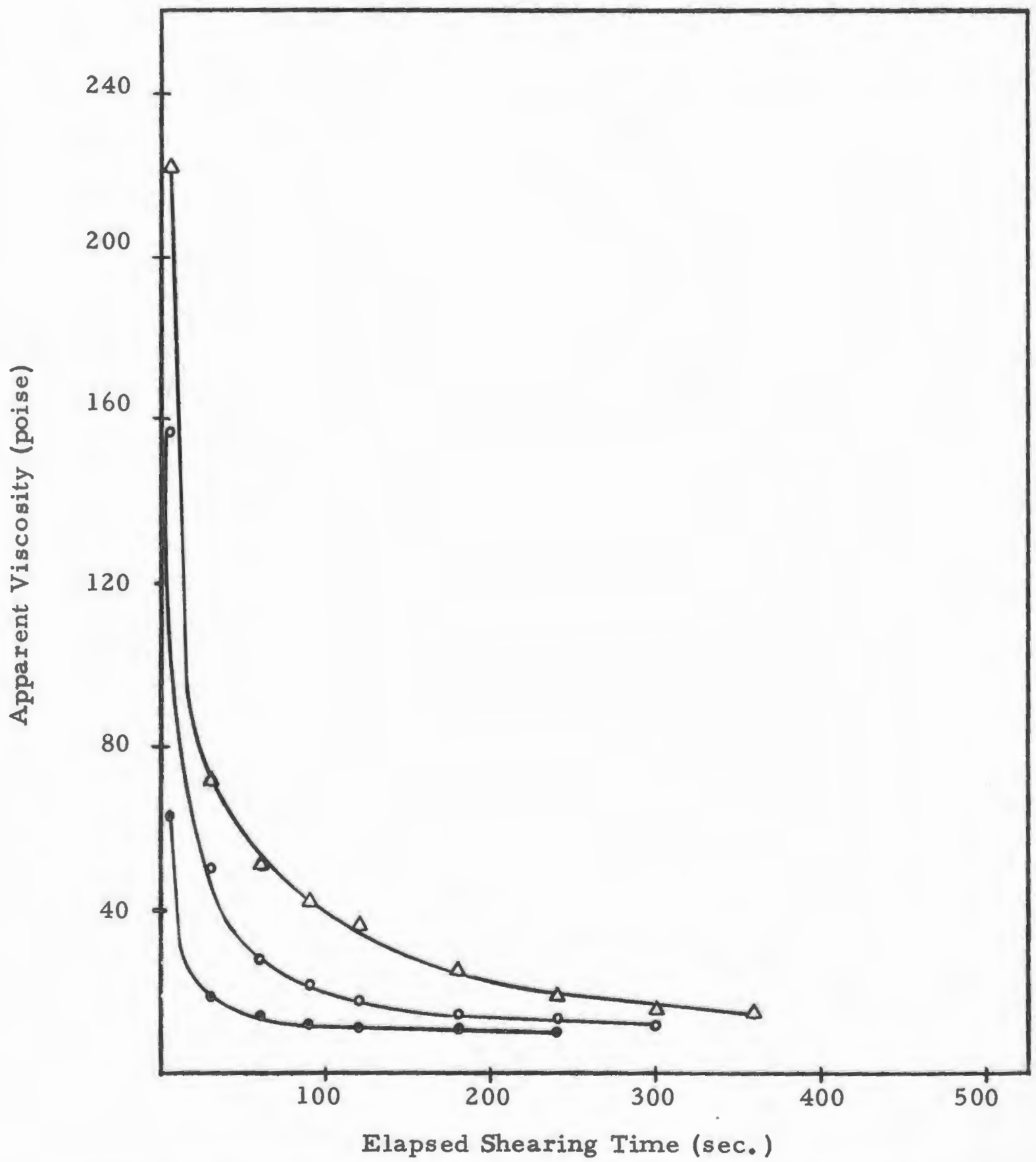

Figure 6. Apparent Viscosity (poise) at $25^{\circ} \mathrm{C}$. versus Elapsed Shearing Time (sec.) for the various grades of Cab-O-Sil at a concentration of $0.5 \%$. All runs made at a shearing stress 7570 dynes / $\mathrm{cm}^{2}$ with sample age -2 - days. $(\bullet=\mathrm{CDL}-5 ; \Delta=\mathrm{M}-5 ; 0=\mathrm{EH}-5)$ 
TABLE IV

THE EFFECT OF PARTICLE SIZE OR SPECIFIC SURFACE OF COLLOIDAL SILICA ON THE APPARENT VISCOSITY(a) OF WHITE PETROLATUM

\begin{tabular}{lccc}
\hline $\begin{array}{l}\text { Elapsed } \\
\text { Shearing } \\
\begin{array}{c}\text { Time } \\
\text { (sec.) }\end{array}\end{array}$ & Grades of Cab-O-Sil (b)(c) & \\
\hline 6 & CDL-5 & M-5 & EH-5 \\
30 & 63.60 & 222.40 & 157.80 \\
60 & 18.90 & 72.80 & 50.50 \\
90 & 14.95 & 50.50 & 28.10 \\
120 & 12.46 & 42.80 & 22.25 \\
180 & 11.85 & 36.40 & 18.48 \\
240 & 11.10 & 26.56 & 14.12 \\
300 & 11.10 & 19.70 & 12.12 \\
360 & - & 16.90 & 11.10 \\
\hline
\end{tabular}

(a) Apparent viscosities in poises. Values shown represent average of at least two runs.

(b) Age of all samples -2- days.

(c) Concentration of samples $0.5 \%$. 
pected that as average particle diameter of a given weight of a solid material is decreased, an increase of specific surface will occur; also, it follows that an increase of the number of particles present can be anticipated. Therefore, because of this existing relationship, it was assumed that if the particle diameter were decreased, an increase of apparent viscosity should occur. However, as shown in Table IV and Figure 6, the results obtained for the EH-5 grade do not coincide with this theory. One possible explanation for the anomalous results obtained in this case might be that the initial dispersion of the EH -5 grade in the petrolatum was not complete due to its unique physical characteristics and the fact that this process is highly dependent upon the limitations of the dispersing instrument. A second explanation might be that subsequent particle agglomeration may have occurred. Tendency for particle agglomeration for the EH-5 grade is greater than for either the CDL-5 or M-5 grades because at any given concentration, the EH 5 grade would have the greatest number of particles present. Consequently, if either or both of these occurred, the effective specific surface would be decreased. This would result in a decrease of apparent viscosity, and a tendency for values of the EH-5 grade to approach those for the CDL-5, which has a larger particle diameter and a smaller specific surface:

The contention that particle agglomeration may have occurred can be substantiated further by the data shown in Figure 7 and Table V, which show that the apparent viscosities for the EH-5 grade are closer 


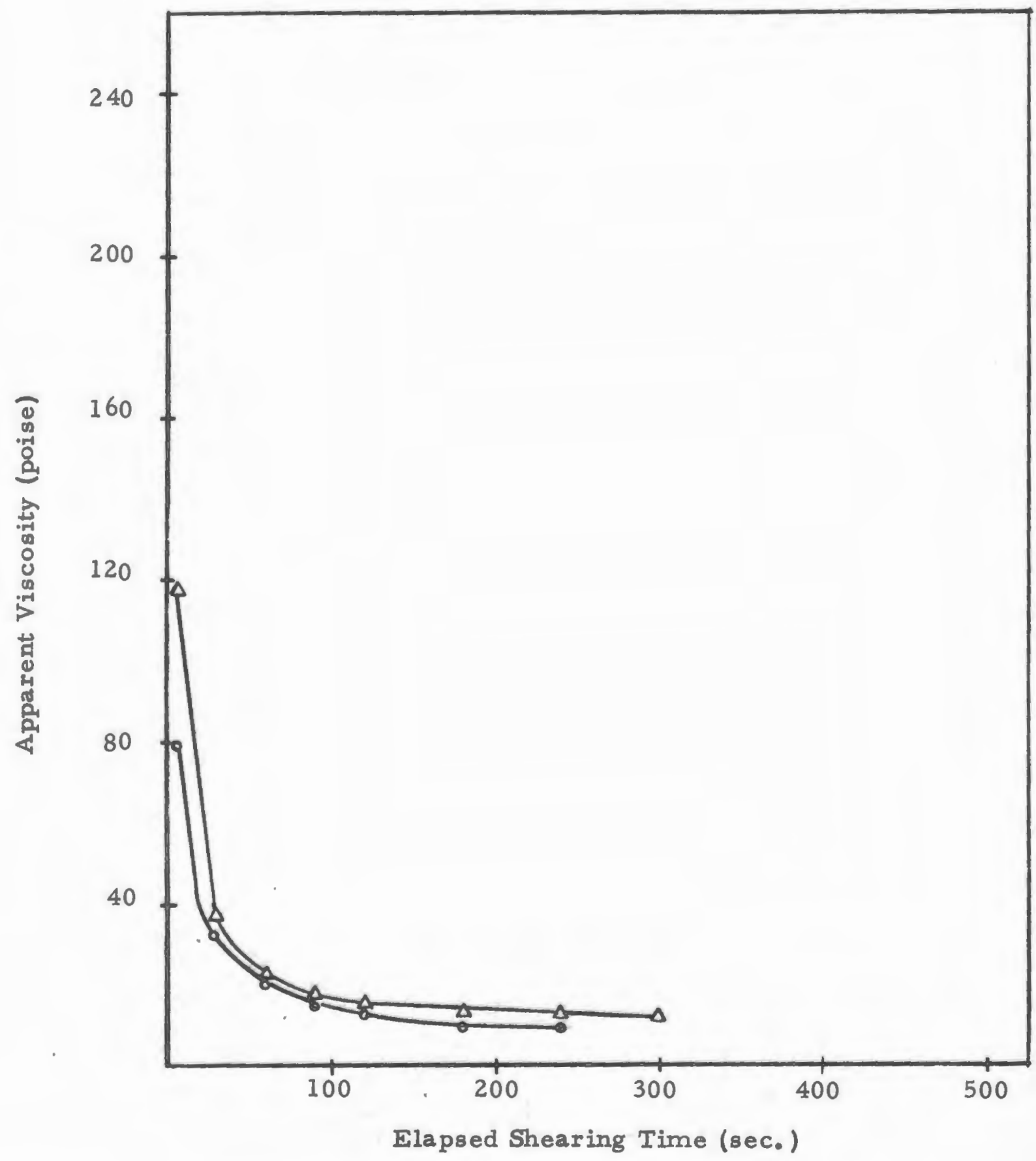

Figure 7. Apparent Viscosity (poise) at $25^{\circ} \mathrm{C}$. versus Elapsed Shearing Time (sec.) for the various grades of Cab-O-Sil at a concentration of $0.25 \%$. All runs made at a shearing stress of 7570 dynes/cm. with sample age -2-days. $(\Delta=\mathrm{M}-5 ; 0=\mathrm{EH}-5$ ) 
TABLE V

THE EFFECT OF PARTICLE SIZE OR SPECIFIC SURFACE OF COLLOIDAL SILICA ON THE APPARENT VISCOSITY(a) OF WHITE PETROLATUM

\begin{tabular}{lcc}
\hline $\begin{array}{l}\text { Elapsed } \\
\text { Shearing } \\
\text { Time } \\
\text { (sec.) }\end{array}$ & Grades of Cab-O-Sil (b)(c) & \\
\hline 6 & 116.50 & SH-5 \\
\hline 30 & 37.80 & 38.10 \\
60 & 23.65 & 20.90 \\
90 & 17.85 & 16.10 \\
120 & 16.10 & 13.05 \\
180 & 14.50 & 10.57 \\
240 & 13.45 & 9.71 \\
300 & 13.45 & - \\
\hline (a) Apparent viscosities in poises. Values shown represent \\
average of at least two runs.
\end{tabular}


to the $M-5$ grade at a concentration of $0.25 \%$. That is to say that, at a lesser concentration, the tendency for particle agglomeration within the EH-5 grade would be less because the number of particles present would be less. Therefore, the effective specific surface would more closely approximate the expected specific surface and the apparent viscosities would be correspondingly greater. Also, it was noted that if the concentration of solid material was increased to $1 \%$, the apparent viscosity values obtained for the EH-5 grade would be nearer to the CDL -5 grade than to the M-5 grade, which is a possible indication that particle agglomeration is greater at the higher concentration of solid material.

Effect of Aging - Tables VI and VII show that an increase of apparent viscosity occurred as the samples were allowed to age. Figures 8 and 9 illustrate the degree to which thixotropic recovery probably took place within these representative samples for the time allotted. The increase of apparent viscosity with sample aging may be indicative of the structural realignment of the $n$, iso, and cyclic paraffins upon standing (11): It is also possible that there was a return of these forms to the complex gel structure attached through random entanglement and chemical bonding (12). 
TABLE VI

THE EFFECT OF SAMPLE AGING

ON THE APPARENT VISCOSITY(a) OF

WHITE PETROIAATUM

\begin{tabular}{lccc}
\hline $\begin{array}{c}\text { Elapsed } \\
\text { Shearing } \\
\begin{array}{c}\text { Time } \\
(\text { sec. })\end{array}\end{array}$ & 0 & Age of Sample (days) & 16 \\
\hline 6 & 68.80 & 2 & 116.50 \\
30 & 19.70 & 72.80 & 32.90 \\
60 & 13.45 & 25.50 & 18.45 \\
90 & 10.81 & 16.90 & 15.38 \\
120 & 9.91 & 13.45 & 13.05 \\
150 & 9.15 & 11.55 & 11.52 \\
180 & 8.50 & 10.57 & 10.55 \\
\hline
\end{tabular}

(a) Apparent viscosities in poises. Values shown represent average of at least two runs. 


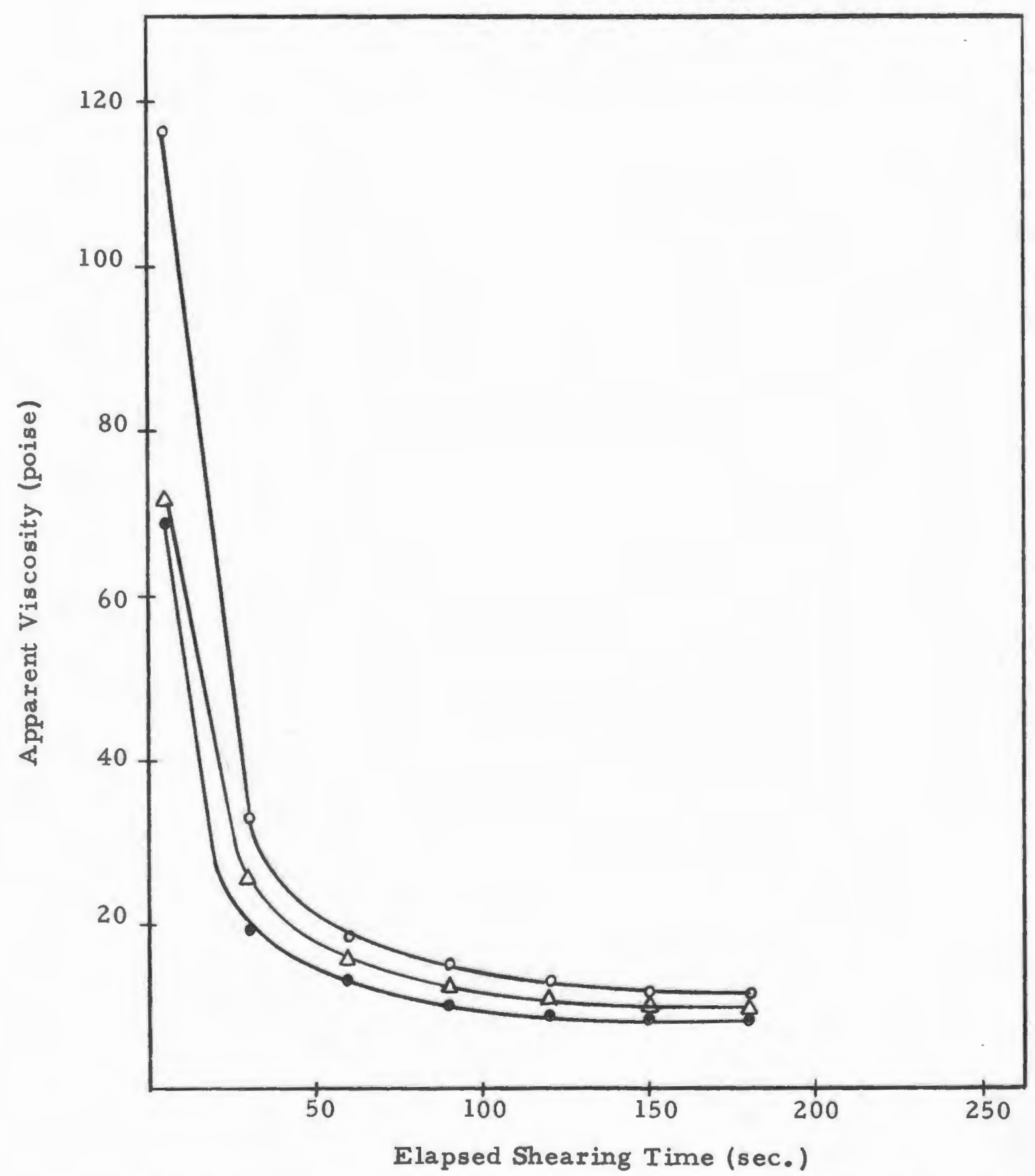

Figure 8. Apparent Viscosity (poise) at $25^{\circ} \mathrm{C}$. versus Elapsed Shearing Time (sec.) for three sample ages of White Petrolatum. All runs made at a shearing stress of 7570 dynes $/ \mathrm{cm} .2$ ( $\bullet=-0$ - day; $\Delta=-2$ - days; $0=-16$ - days) 
TABLE VII

THE EFFECT OF SAMPLE AGING ON THE APPARENT VISCOSITY ${ }^{(a)}$ OF A MIXTURE OF COLLOIDAL SILICA ${ }^{(b)}$ (CAB-O-SIL GRADE EH-5) AND WHITE PETROLATUM

\begin{tabular}{|c|c|c|c|}
\hline \multirow{2}{*}{$\begin{array}{l}\text { Elapsed } \\
\text { Shearing } \\
\text { Time } \\
\text { (sec.) }\end{array}$} & \multicolumn{3}{|c|}{ Age of Sample (days) } \\
\hline & 0 & 2 & 16 \\
\hline 6 & 222.60 & 252.20 & 252.20 \\
\hline 30 & 78.10 & 84.10 & 92.30 \\
\hline 60 & 63.60 & 68.80 & 78.10 \\
\hline 90 & 54.50 & 58.70 & 68.80 \\
\hline 120 & 47.30 & 47.30 & 59.20 \\
\hline 180 & 33.90 & 37.90 & 45.10 \\
\hline 240 & 22.80 & 28.90 & 36.40 \\
\hline 300 & 17.50 & 20.42 & 27.70 \\
\hline 360 & 15.40 & 16.60 & 21.80 \\
\hline 420 & 14.12 & 14.95 & 18.45 \\
\hline 480 & - & 13.05 & 16.60 \\
\hline 540 & - & - & - \\
\hline
\end{tabular}

(a) Apparent viscosities in poises. Values shown represent average of at least two runs.

(b) Concentration of samples $1 \%$. 


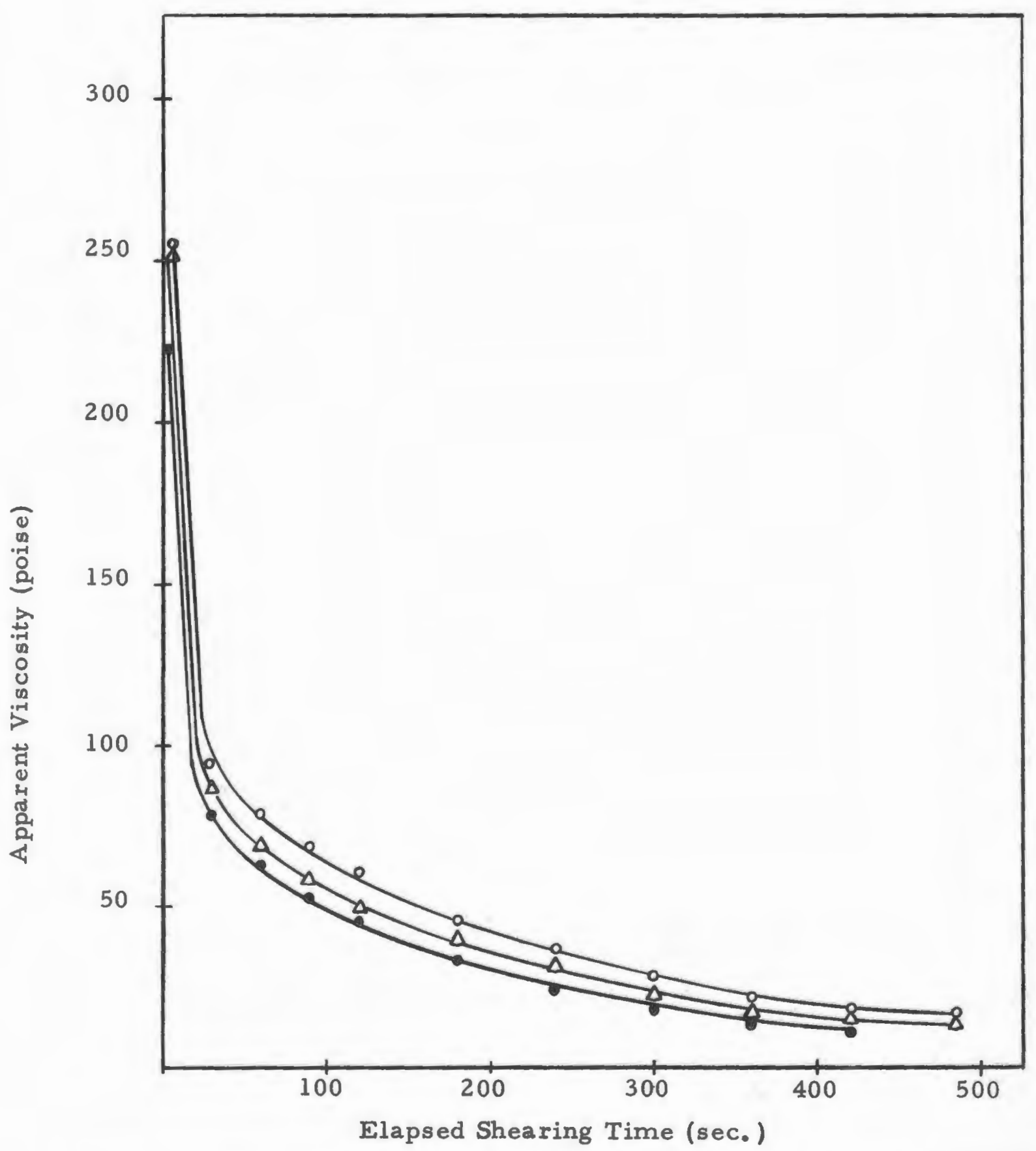

Figure 9. Apparent Viscosity (poise) at $25^{\circ} \mathrm{C}$. versus Elapsed Shearing Time (sec.) for three sample ages of Cab-O-Sil, Grade EH-5, at a concentration of $1.0 \%$. All runs made at a shearing stress of 7570 dynes $/ \mathrm{cm}^{2}$ $(\bullet=-0$ - day; $\Delta=-2$ - days; $0=-16$ - days $)$ 


\section{CONCLUSIONS}

1. As the concentration of colloidal silica within petrolatum was increased, there was a corresponding increase in apparent viscosity for the ointments, regardless of grade used.

2. Usually as particle size of colloidal silica was decreased, apparent viscosity of the ointments increased, although a direct relationship between particle size and apparent viscosity could not be established.

3. Apparent viscosity decreased with elapsed shearing time for all systems.

4. Apparent viscosity increased directly with the age of the sample which was probably indicative of thixotropic recovery. 


\section{REFERENCES}

1. Kostenbauder, H. B., and Martin, A. N., I. Am. Pharm. Assoc,, Sci. Ed., 43, 401-7, (1954).

2. Boylan, J. C., J. Pharm. Sci., 55, 710-15, (1966).

3. Schulte, K. E., and Kassem, M. A., Pharm. Acta Helv., 38, 358, (1963).

4. Boylan, J. C., I. Pharm. Sci., 56, 1164-8, (1967).

5. Kostenbauder, H. B., and Martin, A. N., J. Am. Pharm. Assoc., Sci. Ed., 吕, 401-7, (1954).

6. Ibid.

7. McKennell, R., Analytical Chemistry, 28, 1710, (1956).

8. Van Wazer, J. R., Lyons, J. W., Kim, K. Y., and Colwell, R, E., Viscosity and Flow Measurement, Interscience Publishers, New York, (1963).

9. Kostenbauder, H. B., and Martin, A. N., J. Am. Pharm. Assoc., Sci. Ed., 43, 401-7, (1954).

10. Boylan, J. C., J. Pharm. Sci., 56, 1164-8, (1967)

11. Schulte, K. E., and Kassem, M. A., Pharm. Acta Helv., 38, 358, (1963).

12. Boylan, loc. cit. 